\title{
PRÁTICAS LEITORAS EM MINAS GERAIS, SÉCULO XIX: BIBLIOTECAS PÚBLICAS E LEITURA DE JORNAIS ${ }^{1}$
}

\author{
READING PRACTICES IN MINAS GERAIS DURING \\ THE XIX CENTURY: PUBLIC LIBRARIES AND \\ NEWSPAPERS READING
}

\author{
Flávia Silvestre Oliveira* \\ Maria da Conceição Carvalho**
}

\begin{abstract}
RESUMO
Introdução: O fim da proibição das atividades de impressão no Brasil, em 1808, provocou o aparecimento de grande número de jornais, deflagrando debates políticos e a propagação da prática de leitura informativa e literária.

Objetivo: Investigar a ocorrência de práticas de leitura em Minas Gerais, no século XIX, especialmente a leitura de jornais em bibliotecas públicas das cidades de Ouro Prêto e São João del Rey.

Metodologia: Revisão de literatura sobre História da Leitura, dialogando, sobretudo, com Darnton, Chartier, Abreu, Lajolo e Zilberman. Enquanto estudo com características de micro-história, definiu-se para a coleta de dados jornais publicados naqueles locais, no período, assim como documentos oficiais, e impressões de viajantes estrangeiros. Para a análise dos dados utilizou-se a análise documental.
\end{abstract}

Resultados: As bibliotecas públicas foram responsáveis por facilitar o acesso dos habitantes da província à prática da leitura, em especial a leitura de jornais. Através das colunas do leitor criou-se um canal de participação política e de sociabilidade entre cidadãos de diferentes cidades do país.

Conclusões: A sociedade mineira do século XIX, como já vinha acontecendo desde os movimentos da Inconfidência, fez da leitura de jornais um ato cotidiano vivido por indivíduos de diferentes classes sociais. Nas bibliotecas e sociedades literárias, como nas praças públicas, jornais e folhetos eram lidos

\footnotetext{
1 Este artigo foi elaborado como parte da dissertação de Flávia Silvestre de Oliveira defendida no Programa de Pós-Graduação da Escola de Ciência da Informação da UFMG em 2014 com orientação da Profa. Dra. Maria da Conceição Carvalho.

*Mestre em Ciência da Informação da Universidade Federal de Minas Gerais. E-mail: fsilvestre.oliveira@gmail.com

${ }^{* *}$ Doutora em Literatura Comparada pela Universidade Federal de Minas Gerais (UFMG). Professora da Escola de Ciência da Informação da UFMG. E-mail: daccar@gmail.com
}

Inf. Inf., Londrina, v. 21, n. 1, p. $426-447$, jan./abr. 2016.

http:www.uel.br/revistas/informacao/ 
em voz alta para proveito das pessoas mais pobres e iletradas que foram, de alguma forma, socialmente inseridas naquele momento de mudanças sociais e políticas.

Palavras-chave: Minas Gerais. História da leitura. Século XIX. Bibliotecas públicas. Leitura de jornais. Séc XIX.

\section{INTRODUÇÃO}

A chegada da Corte portuguesa ao Rio de Janeiro, em 1808, representou, como é sabido, uma verdadeira transformação no cenário econômico-social e cultural brasileiro onde, até então, tudo era precário, das estruturas físicas à oferta de serviços. De fato, o rarefeito aparato social e cultural encontrado pelo príncipe regente na capital da colônia não era suficiente para atender às demandas de um governo imperial, de maneira que Dom João VI viu-se obrigado a fazer certas concessões que contrariavam o Pacto Colonial e que, sem dúvida, significaram uma nova fase de desenvolvimento na história brasileira. Entretanto, não cabe aqui comentar todas as importantes medidas políticoadministrativas que D. João VI tomou desde a primeira parada de um mês em Salvador, continuadas após a instalação definitiva na cidade do Rio de Janeiro, como a abertura dos portos às nações amigas, a abertura de secretarias públicas, a instalação de Tribunais de Justiça e criação do Banco do Brasil e do Arquivo Central, entre outras. Interessanos, mais especificamente, nesse artigo, lembrar que a instalação da Imprensa Régia como providência necessária para a publicação de documentos oficiais e materiais de suporte administrativo nos primeiros meses da chegada da Corte significou, paralelamente, a autorização legal para que se utilizasse livremente no Brasil, com histórico atraso, a tecnologia da impressão inventada e fundida na Europa desde o final século XV, como se sabe, e instalada pelos espanhóis nas suas colônias da América desde 1533 (México, 1533; Peru, 1577; Bolívia; 1612). Antes proibidas oficialmente pelo estado censor português, que limitava de todas as maneiras a liberdade de pensamento na América 
Português, as tipografias se multiplicam no Rio de Janeiro e nas províncias a partir daquele ano de 1809 sendo interessante notar que a criação de grande número de jornais ou folhas periódicas deflagra um novo impulso na propagação das ideias políticas e da leitura de obras literárias por diferentes camadas da população, como veremos a seguir.

\section{AMBIENTES E PRÁTICAS DE LEITURA NO RIO DE JANEIRO E NA PROVÍNCIA DE MINAS GERAIS NA PRIMEIRA METADE DO SÉCULO XIX}

A vinda de nobres e burgueses junto com a Corte para o Rio de Janeiro estimulou de fato, em certa medida, novas práticas de leitura na capital do Império. A historiadora Márcia Abreu menciona a existência de uma verdadeira febre de leitura do romance na cidade carioca por aquela época, cujos títulos, na sua maioria, eram primeiramente publicados em jornais, em forma de fascículos, e só depois em formato de livro (ABREU, 2006) como ocorria também no cenário cultural europeu.

Ao mesmo tempo, a criação de algumas instituições de ensino superior na cidade também contribuiu para um aumento do consumo de livros, tanto didáticos como literários, incentivando não apenas a impressão de obras pela Impressa Régia mas impulsionando também a importação de livros editados na Europa.

No que diz respeito à província de Minas as primeiras décadas do século XIX iriam significar o grande desafio de superar um quadro socioeconômico preocupante, devido à decadência da exploração do ouro e, ao mesmo tempo, à necessidade de acompanhar a exigência de modernização tecnológica e cultural que se apresenta após a instalação da Corte imperial Portuguesa no Rio de Janeiro.

Sobretudo a partir da Independência do Brasil, em 1822 (mas já presente no ideário dos Inconfidentes Mineiros no final do século XVIII), espalha-se por todo o país o ideal de construção de uma nação 
intelectualmente desenvolvida, tal qual as "grandes" nações europeias, onde ao menos a instrução elementar fosse destinada à maioria da população. Contudo, apesar da profusão de discursos em prol do progresso e da civilização na prática predominou a herança de um sistema educacional profundamente debilitado, em muitos casos resumindo-se a um amontoado de aulas avulsas funcionando em lugares inadequados, sem profissionais qualificados. Para as pesquisadoras Mariza Lajolo e Regina Zilberman embora a Constituição de 1824 na regência de $D$. Pedro I incluísse instrução primária e gratuita a todos os cidadãos não houve, de fato, uma verdadeira transformação na estrutura educacional perdurando a precariedade da educação e a consequente carência no âmbito da leitura (LAJOLO; ZILBERMAN, 1998, p. 136).

Mas, apesar desse panorama educacional repleto de problemas e descontinuidades, é interessante observar que outras instituições teriam sido protagonistas nesse processo de desenvolvimento da cultura letrada nas Minas oitocentistas. Bibliotecas públicas, que serão abordadas neste artigo, assim como gabinetes e sociedades literárias ${ }^{2}$ aparecem em documentos históricos como responsáveis pela difusão da leitura em diferentes suportes nas maiores vilas da Província, como consequência de um esforço da elite financeira local que almejava ser reconhecida socialmente como elite intelectualizada e afeita à prática da filantropia.

Neste artigo visitaremos as duas mais importantes cidades mineiras no período em foco, São João del Rey e Ouro Preto.

A Vila de São João del Rey era um espaço urbano bastante ativo na primeira metade do século XIX conforme nos conta a pesquisadora Christiani de Morais, sendo um dos principais centros de exportação dos produtos mineiros, além de se encarregar da distribuição dos produtos

2 Segundo o pesquisador Luciano da Silva Moreira (2006) no período 1831-1834 havia registro de 34 sociedades literárias em Minas Gerias. 
trazidos da Corte atuando, pois, como um entreposto comercial (MORAIS, 2002, p. 1). Ocupava uma posição geográfica privilegiada, com uma malha privilegiada de estradas e caminhos e, por tudo isso, era a sede administrativa da Comarca do Rio das Mortes. No que se refere aos aspectos culturais informa Morais na mesma fonte, citando Maria Augusta A. Campos (CAMPOS, 1998) que a partir da instalação de sua primeira tipografia em 1827, a Vila de São João del Rey foi palco de uma explosão de folhas locais, tendo sido publicados doze periódicos entre os anos 1827 e 1844. Como entender essa proliferação da palavra impressa numa época com altíssimo grau de analfabetismo em todo o país? Como acontecia desde a Idade Média europeia, a leitura comunitária em voz alta foi, também, a maneira de permitir a um maior número de pessoas nas províncias mineiras o acesso à informação utilitária e política que circulava através das folhas dos jornais. Márcia Abreu ressalta essa cena comum em diferentes partes do país, inclusive relatada por viajantes estrangeiros, em que "com a mediação de uma pessoa alfabetizada, diversas outras - leitoras ou não - travavam contato com textos escritos." (ABREU, 2006, p. 90).

Vila Rica foi fundada em 1711 em meio à corrida do ouro, metal precioso que se revelou ali tão abundante que "entre 1700 e 1770 a produção do Brasil foi praticamente igual a toda a produção de ouro do resto da América, verificada entre 1493 e 1850, e alcançou cerca de $50 \%$ do que o resto do mundo produziu nos séculos XVI, XVII e XVIII" (ROBILARD; RAMOS, 2016, p. 1). A exploração predatória e o descaso do Governo em dotar o novo núcleo urbano dos recursos terminou por exaurir as minas seguindo-se um período de fome e de conflitos sociais. Tal decadência, entretanto, não incidiu muito drasticamente sobre a vida social e cultural da cidade que continuou exibindo um fausto ligado à religiosidade e um ambiente intelectual notável para a província. Sobretudo após a independência ganha fôlego entre os intelectuais mineiros o projeto de construção de um país com identidade própria, que quer se desligar do jugo da herança civilizatória lusitana. Reforça-se 
o sentimento de independência e liberdade e a crença de que um Estado Nação de constrói através do direito à educação e à leitura que informa.

\section{AS PRIMEIRAS BIBLIOTECAS PÚBLICAS MINEIRAS}

De acordo com o historiador Luiz Carlos Villalta, pesquisador da história leitura no Brasil é correto dizer que no conjunto da sociedade brasileira predominou o desprestígio da educação escolar embora não se possa negar alguma forma de apoio à escola na Colônia, apoio que "variou conforme os grupos sociais, os espaços e tempos, tendo crescido no século XVIII, particularmente em Minas Gerais, favorecida pelo florescimento de uma civilização urbana com um expressivo setor de serviços." (VILLALTA, 1997, p. 354). Ressalta, contudo, a dificuldade que representa para um historiador "avaliar o apreço pela instrução escolar no Brasil colonial" acrescentando ser possível apenas "alinhavar algumas impressões sobre a região sudeste, a partir de meados do século XVIII." (VILLALTA, 1997, p. 354). Nesse sentido informa que, regra geral, tal valor dado à educação escolar ou, à instrução, seria demonstrado, ainda que de forma irregular, pelas elites, entre proprietários de terras e lavras e grandes comerciantes (VILLALTA, 1997, p. 354-355).

\subsection{A biblioteca pública de São João del Rey}

De fato, é a um rico comerciante da vila mineira de São João del Rey que se atribui a fundação da primeira biblioteca pública de Minas Gerais. Em 1827 o comerciante Baptista Caetano d'Almeida, com a aprovação e o apoio de outras figuras importantes da localidade, funda ali uma biblioteca pública motivado a estimular na sua terra o desenvolvimento de uma civilização nos moldes europeus do século das Luzes, capaz de superar a falta de ilustração do país. Contudo, subjacente àquele ato benemérito e cultural estaria, ainda, a clara 
tentativa de se construir uma demarcação social entre eles, figuras da elite, e a massa de pessoas comuns e iletradas.

O acervo dessa biblioteca aberta ao público foi constituído, inicialmente, pela própria "livraria" de Baptista Caetano, segundo palavras suas no dia de inauguração:

Conhecendo o estado actual deste paiz, que he falto no todo de illustracção, por não ter havido quem movido de Patriotismo desse o primeiro impulso a hu estabelecimento tão util, como necessario, qual o de huma Livraria Publica, e julgando eu que todas as couzas querem principio, para de pois serem continuadas, muitas vezes com inteiro proveito do Publico. Portanto, cheio da quelle fogo Patriotico, que me inspira o decidido amor do meu Paiz, tenho a honra de offerecer [...] minha pequena livraria [...] para principios de huma Livraria Publica desta Villa (ALMEIDA apud MOTTA, 2000, p. 98).

$E$, ainda que ele tenha se empenhado pessoalmente para que 0 governo provincial se responsabilizasse pela manutenção da biblioteca, não logrou conseguir para tal fim o respaldo do Estado. Foi preciso articular uma doação permanente por parte de figuras importantes da Vila de São João del Rey chamados, na época, de subscritores, para conseguir manter a "livraria" pública.

É o que atesta um aviso publicado em jornal da vila de São João del Rey em que João Baptista Pinto de Almeida, tesoureiro da mesa administrativa da Biblioteca, solicitava:

Aos Srs., que fizeram a filantrópica ação de voluntariamente subscrever para tão útil estabelecimento, que segundo o Regimento feito pela comissão, as ações devem ser pagas hum mês depois das eleições. Mas como isto não será possível a todos, roga aqueles dos Srs. Subscritores a quem for possível entrar com alguma quantidade o façam para poder-se continuar com a despesa de Periódicos, tinta, papel e Empregados, cuja despesa tem até o presente sido feita a crédito (ASTRO DE MINAS, 1827). 
Por muitos anos a biblioteca sobreviveu graças a doações desses subscritores como também da ação benemérita de importantes figuras da elite local, que deixavam em testamento a doação dos livros de suas coleções particulares para a instituição.

O viajante irlandês Robert Walsh (1772-1852), pastor protestante, esteve em Minas em 1828 e, de passagem por São João del Rey visitou a biblioteca pública da vila que considerou "incipiente estabelecimento fundado nas montanhas do Brasil, onde, havia bem pouco tempo, era interdita a difusão de qualquer tipo de conhecimento" (WALSH, 1985, p. 77). Anotou, ainda, no seu diário de viagem, publicado na Inglaterra em 1830, e traduzido no Brasil em 1985 como Noticias do Brasil (1828 1829):

Ela [a biblioteca] se acha instalada numa sala da Câmara, ficando aberta das nove da manhã à uma da tarde. O bibliotecário é um padre mulato, de aparência bastante curiosa - baixo, gordo, com um vasto chapéu colocado de banda e o rosto afundado no peito [...] Além de bibliotecário, ele é editor do 'Astro de Minas', um jornal de São João fundado fazia um ano. [...] [Os livros] somavam cerca de 1.000 volumes dispostos ao longo das paredes, numa sala bem arrumada, comum a mesa de leitura no centro. Além das obras em português e espanhol, havia muitas outras em francês; a "Enciclopedie", obras de Voltaire, Rousseau e Raynal, juntamente com outras que apareceram na fase final da Revolução Francesa. Ficamos surpresos, porém, ao encontrarmos num lugar tão remoto alguns livros ingleses, entre os quais o "Revolucionário Plutarco", " Riqueza das ações" de Smith; "Geografia" de Pinkerton; o "Paraíso Perdido", "Viagem Sentimental" e " Trials for Adultery", ao lado de alguns periódicos, entre eles o Times e o Chronicle (WALSH, 1985, p. 77).

Embora a visão dos viajantes estrangeiros sobre a vida cultural no país tenha sido quase sempre pejorativa, percebendo-a "degradada, desinteressante e inadequada." (ABREU, 2006, p. 84) Walsh se desprende do eurocentrismo comum aos viajantes europeus e destaca, no seu diário, a importância do acervo de periódicos naquela biblioteca pública de uma remota província: "Além desses periódicos [os jornais 
ingleses Times e Chronicle] todos os jornais publicados no Brasil são recebidos e colocados na sala de leitura". (WALSH, 1985, p. 77).

No que se refere ao tipo de material bibliográfico que chegava á biblioteca em forma de doação é preciso destacar, também, as recorrentes doações de periódicos. Segundo notícias publicadas no jornal local Astro de Minas tornaram-se conhecidos os nomes dos cidadãos beneméritos e dos periódicos que colocavam à disposição dos conterrâneos daquela província:

O nosso benemérito Patriota, Estêvão Alves de Magalhães foi aquele que por sua particular amizade com o Cidadão Loureiro, alcançou tão grandiosa oferta para o nosso novo estabelecimento. Este honrado Patrício continua a enviar à Livraria em todos os correios os Periódicos da Corte e muitos das diversas Províncias do Império, e não se tem poupado à despesas, para conseguir o melhoramento, e aumento de nossa Biblioteca.

[...] O ilustre Cidadão, o Sr. Cônego Januário, tem sido constante remeter à nossa Biblioteca as diversas folhas francesas que recebe, e desta sorte concorre para a ilustração do nosso país [...] (ASTRO DE MINAS, 1830).

O desejo de disponibilizar a um maior número de leitores aquela rica coleção de periódicos teria sido o motivo pelo qual a biblioteca, nove anos após a inauguração, passou a funcionar também nos dias santos. Um registro, ou mais precisamente, um aviso publicado no jornal Astro de Minas, em 09 de junho de 1831, informava a população sobre a abertura da Biblioteca nos dias santos, no período da tarde, visando atender "a maioria dos Cidadãos desta Villa [que não podiam] aproveitar-se da leitura dos periódicos nos dias úteis pela complicação dos seus empregos" ressaltando o fato de que não haveria apenas "os jornais da Província como os da Corte, e de outras algumas Províncias" (ASTRO DE MINAS, 1836).

O horário de funcionamento dessa biblioteca pública variou ao longo dos anos, mas sempre manteve ao menos meio expediente em que atendia a todos que assim quisessem, desde que vestidos 
decentemente. Em suas dependências não era permitido falar alto ou conversar principalmente quando outros estavam nas salas de estudo e era exigido dos leitores uma leitura silenciosa, própria de leitores intelectualizados que podiam ler de forma autônoma.

Assim, sem apoio financeiro por parte de Estado ${ }^{3}$, sem receita própria para atualização do acervo, manutenção do espaço e pagamento de funcionários, a biblioteca se mantinha por meio de doações, o que, para a pesquisadora Morais (2002) seria evidência da natureza da relação estabelecida pelo governo brasileiro com essas instituições culturais: "Ao mesmo tempo em que o império do Brasil queria se inserir na modernidade, ser reconhecido como um país 'civilizado' nos moldes europeus, temia que ações desse tipo fugissem do seu controle" (MORAIS, 2002, p. 78).

O acervo original dessa primeira biblioteca pública de Minas está preservado em parte, sendo hoje referência para estudiosos da história cultural de Minas Gerais por abranger um grande número de obras consideradas raras.

\subsection{A Biblioteca Pública de Ouro Preto}

A Biblioteca Pública da antiga Vila Rica, capital da Província de Minas, teria sido fundada em 1831 pela Sociedade Promotora da Instrução Pública da cidade, a partir de um Gabinete de Leitura que ali existira de 1821 a 1825, transformado então "em uma pequena livraria", conforme notícia publicada no jornal Astro de Minas (1832).

Há notícias de que o seu acervo se constituía, principalmente, de periódicos e livros adquiridos por meio de doações, já que herdados da Sociedade Literária, cujas obras para consulta, segundo o pesquisador Luciano da Silva Moreira (MOREIRA, 2006, p. 144) haviam sido doadas

\footnotetext{
3 Por força da Lei no. 49, de 08 de abril de 1836 as bibliotecas públicas de São João del Rey e de Ouro Preto passaram a ser geridas em parte pelo Estado que regulamentou a forma de funcionamento das duas instituições.
} 
ou compradas através "do auxílio pecuniário de seus sócios." Segundo a mesma fonte (MOREIRA, 2006, p. 144), "a ilustração pública figurava como um dos objetivos latentes" dessa biblioteca, assim como também o era da Sociedade Promotora da Instrução Pública, entidade responsável por sua manutenção.

Embora pequena a biblioteca pública de Ouro Preto, vai ser reconhecida como lugar de prestígio social e cultural que sua existência implicava. Em artigo publicado também em Astro de Minas no mesmo ano de 1831, o redator enumera algumas instituições relacionadas à cultura letrada no país, tais como tipografias, universidades e bibliotecas, destacando bibliotecas em São Paulo, Rio de Janeiro, Bahia, Pernambuco e Maranhão e duas em Minas, "uma nessa vila [São João Del Rey] e outra em Ouro Preto" ( ASTRO DE MINAS, 1831).

O Universal, jornal editado em Ouro Preto, informava em 1831 sobre o acesso à leitura na biblioteca onde se lia livros e também os "periódicos desta Província, com mui poucas exceções, a maior parte do Rio de Janeiro, e alguns das outras províncias" (O UNIVERSAL, 1831).

Contudo a primeira lei, de que se tem conhecimento, relativa às normas de funcionamento da instituição, foi aprovada apenas em 1836, quando se criou uma legislação que tratava especificamente das diretrizes relacionadas ao uso e funcionamento das bibliotecas de São João del Rey e da capital Ouro Preto. Neste ano ambas passaram a ser geridas, ao menos em parte, pelo Estado que, por meio da Lei Mineira de número 49, de 08 de abril de 1832, regulamentou a forma de funcionamento das duas bibliotecas (LIVRO DA LEI MINEIRA, 1836).

As funções dos funcionários das bibliotecas constam no artigo II que previa as competências que cabiam à eles. Segundo tal legislação aos bibliotecários incumbia: a guarda e segurança da instituição; "o bom regime"; asseio e economia interna; o arranjo e classificação de todos os livros, os quais deveriam ser rubricados pelo Presidente da Câmara Municipal. 
Conforme o artigo III competia ao contínuo: manter os livros sempre limpos, assim como "ministrá-los as pessoas, que concorrerem à Biblioteca; fazer o serviço da sala; abrir e fechar as portas às horas marcadas neste Regulamento."

Os artigos IV, V, VI diziam sobre o cumprimento da jornada de trabalho dos funcionários:

Art. IV. Tanto o Bibliotecário, como o Contínuo são obrigados á comparecer na Biblioteca todos os dias, e às horas declaradas no artigo VII.

Art. V. O Bibliotecário perceberá a gratificação anual de cento e cinquenta mil réis, e terá, pago à sua custa, o contínuo, que será por ele nomeado, sob sua responsabilidade.

Art. VI. No impedimento de qualquer dos referidos Empregados, trará suas vezes o outro, e no de ambos, que será participado á Câmara Municipal respectiva pelo Bibliotecário, e substitua, e que vencem a terça parte de gratificação deduzida da do Bibliotecário (LIVRO DA LEI MINEIRA, 1836).

Já o capítulo II do regimento informava especificamente sobre o regime interno das Bibliotecas e o horário de funcionamento das mesmas. Segundo o artigo VII essas instituições deveriam estar "abertas desde as oito horas da manhã até o meio dia, e desde as duas da tarde até o por do sol todos os dias, que não forem Domingos, e Dias Santos, ou de Festividades Nacional". (LIVRO DA LEI MINEIRA, 1836).

Ainda conforme tal lei, a entrada era permitida a todas as pessoas, desde que "decentemente vestidas, franqueando-se-lhes os livros que pedirem, penas, e tinta". Os empréstimos domiciliares eram proibidos e todo o manejar de livros deveria ser feito apenas pelos contínuos.

Nem uma das pessoas admitidas poderia tirar os Livros das Estantes, ou restituí-los á elas, devendo para isso dirigir-se ao Contínuo, á quem pelo Artigo III incumbe este trabalho. Também não se poderá emprestar Livro algum para fora das Bibliotecas, sob pena de ser restituído pelo Bibliotecário, ou a obra inteira, quando 
conste de mais de um volume (LIVRO DA LEI MINEIRA, 1836).

Ainda constava na lei a proibição das conversas nos ambientes onde se realizava a leitura e os estudos, sob o risco de sofrer as penas de advertência e expulsão da biblioteca. Conforme o artigo IX,

[...] a nem uma pessoa, tanto das admitidas, como das empregadas, será permitido passear, ou conversar em alta voz na sala da Biblioteca, quando outros estiverem lendo, ou escrevendo na mesma sala" e "se não obedecer a esta disposição sendo para isso advertida, será expulsa (LIVRO DA LEI MINEIRA, 1836).

O documento ainda previa a questão das doações de livros e outros materiais: "Art. XI. Os Bibliotecários farão constar pelas folhas publicas as doações de livros e outros objetos, que por ventura foram feitas às Bibliotecas por quaisquer pessoas, declarando seus nomes." (LIVRO DA LEI MINEIRA, 1836).

Tal diretriz, se, por um lado, pretendia moldar um novo leitor, por outro lado liberava o Estado de outras obrigações a não ser do pagamento de uma pequena quantia a ser destinada para manutenção dessas instituições (LIVRO DA LEI MINEIRA, 1836).

Em 1848, foi aprovada a resolução de número 430, de 21 de outubro que tornava a biblioteca pública responsabilidade da Assembleia Legislativa Provincial e também estabelecia outras disposições a respeito de seu funcionamento. Conforme 0 artigo primeiro tal mudança previa ainda que tal Assembleia seria responsável por alocar a biblioteca em novo local: "a Biblioteca Pública da Capital fica d'ora em diante adida à Secretaria da Assembleia Provincial sob a inspeção do Oficial Maior da mesma Secretaria, que a colocará no lugar mais próprio." (LIVRO DA LEI MINEIRA, 1836).

O horário de funcionamento da biblioteca também foi estabelecido pelo regulamento, cabendo ao bibliotecário zelar pelo seu cumprimento. Ao que tudo indica a função de contínuo não existia mais, 
sendo absorvida pelo bibliotecário que receberia, no entanto, uma gratificação. Conforme o artigo $2^{\circ}$ :

O bibliotecário é obrigado a franquear ao público a Biblioteca todos os dias uteis desde as nove horas da manhã até as duas horas da tarde, e responder pela guarda e conservação dos livros, percebendo por este aumento de trabalho uma gratificação anual de duzentos mil reis (LIVRO DA LEI MINEIRA, 1836).

Ainda, conforme o regulamento, seriam disponibilizados, pelo governo, para a compra de acervos, dois contos de réis, com os quais deveriam ser gastos mandando "vir da Europa os livros e revistas de mais merecimento nos diversos ramos das ciências, especialmente de administração" e também recolhendo a dita "biblioteca as duplicatas que existirem na da cidade de S. João Del Rei, indenizando-a de seus valores pela quota do artigo antecedente". (LIVRO DA LEI MINEIRA, 1836).

Pode-se perceber duas modificações importantes se comparado ao regulamento n. 9, da lei no 49. Com relação ao horário de funcionamento o mesmo foi reduzido, já que na lei anterior as bibliotecas funcionavam em dois turnos, de oito da manhã até meio dia, e de duas da tarde até o pôr do sol. Talvez porque o número de funcionários também tenha diminuído, sendo todas as funções agora acumuladas pelo bibliotecário (LIVRO DA LEI MINEIRA, 1836).

Apesar de não se possuir informações precisas sobre o acervo acredita-se que tal regulamento era uma tentativa de aumentar as obras editadas no exterior, pois que o estímulo dado foi direcionado à compra de livros vindos da Europa, em um momento em que já existiam livros sendo publicados no Brasil.

Com relação à sua localização sabemos apenas que não se encontrava no centro, conforme relatado por Thobias, na Gazeta de Ouro Preto [s.d], uma vez que em 1839 havia sido aprovada a lei n. ${ }^{0141}$, que previa a transferência do acervo da biblioteca pública para o Colégio 
de Instrução e Educação do Sexo Masculino que seria criado por uma companhia contratada pelo Estado. O interessante é perceber que tal lei não previa apenas a mudança da instituição, mas também, em caso de dissolução da Companhia e fechamento do Colégio, a devolução do acervo ao Estado, hipótese que acreditamos ter-se efetivado, já que em 1848 (LIVRO DA LEI MINEIRA, 1836).

\section{$4 \quad$ LEITORES DE JORNAIS NA PROVINCIA DE MINAS GERAIS}

A fundação daquelas bibliotecas públicas nas duas cidades da província de Minas contribuiu para a expansão de um modo de ler até então específico das elites letradas, uma forma de ler silenciosa e individual, em um espaço voltado especificamente para tal ação, já que ali era exigido, tanto de seus funcionários, quanto de todo o público, o silêncio e a ordem. Mas os jornais, especificamente, foram veículos importantes na difusão da leitura junto a um número maior de cidadãos e estão diretamente relacionados ao surgimento/crescimento entre nós da prática da leitura extensiva, assim denominado pela história cultural, ou seja, a leitura alternada de textos diversos em contraposição à leitura repetida de um ou poucos textos escritos. Além disso o jornal era mais acessível ao leitor deserdado de riqueza material para o qual adquirir livros ainda era muito difícil, mesmo considerando-se a recente abertura dos portos às nações amigas e a instalação de livrarias nas maiores cidades.

Outro papel importante dos periódicos lidos pelos mineiros em bibliotecas públicas ou em espaços menos "nobres" como praças públicas e bares, foi a expansão de debates públicos que se animava naquele momento histórico de conflitos e grandes mudanças sociais.

De fato, o desenvolvimento econômico pós-independência assim como as mudanças sociais colocaram a alfabetização e a leitura (e a leitura especifica de jornais), ao alcance de um público mais diversificado, apesar de continuar atendendo principalmente às elites. É possível, de fato, acreditar que a publicação desses periódicos 
impulsionou a circulação maior de notícias e de ideias, incentivou a discussão política a partir da leitura de jornais e atiçou o gosto pela leitura literária nos rincões mineiros, ainda que se saiba da permanência de enorme contingente de mineiros/brasileiros pobres e analfabetos afastados (até hoje) do ato de ler.

Entre aqueles leitores que adentravam o mundo do impresso alguns podem ser reconhecidos pelos pesquisadores nas páginas desses pequenos jornais, na seção dedicada às cartas do leitor, presentes em praticamente todos esses periódicos. Exemplo disso é uma carta escrita por um tropeiro ao jornal $O$ Universal com o objetivo de defender suas origens que, considerava ele, estavam sendo difamadas:

Vindo eu do meu plácido retiro da Paraopeba a vender alguns dos gêneros de minha roça, no passar pela rua do S. José, rixavão dois [...], e não percebi, que a rixa era contra um sujeito de casaca. No calor da briga ouvi estes gritos: - Ah! Maldito, excomungado nem o Paraopebano é tão falso, tão caluniador, e sem vergonha como tu.- Imediatamente me apiei, e desembaiando a minha cumprida Catana, quis logo punir as mulheres por entender que me atacavam, eis logo acudem muitos sujeitos e me arredam de tal propósito, explicando-me, o que as mulheres diziam [...] Sr. Tropeiro, v. m. está enganado, estas mulheres o não injuriaram; hoje se diz o Paraopebano, o que é mentiroso, caluniador, sem vergonha; deram motivo à esta denominação umas correspondências que apareceram nas Gazetas do Rio (O UNIVERSAL, 1825b).

Os tropeiros pertenciam, regra geral, às classes mais humildes da sociedade mineira do Império e, no entanto, este, cujo codinome era Verdadeiro amante de sua Pátria, mostrou-se um leitor/cidadão ao utilizar o jornal como um canal eficiente para apresentar sua defesa aos moradores da cidade.

O jornal se revela naquele momento como um espaço onde 0 homem comum declara o seu apreço pela leitura. Escrevendo ao jornal O Sul de Minas, publicado na cidade de Campanha de 1859 a 1863, um 
leitor que usava o pseudônimo de Philócorus, descreveu, assim, a leitura minuciosa que fazia do jornal: "amante da leitura não mal emprego o tempo que a ela me dedico: assim, não é de presumir-se que eu tenha deixado despercebido uma só linha de sua apreciável folha e meditado acerca de seu contexto" (O SUL DE MINAS, 1859). Já um leitor do O Universal, publicado em Ouro Preto, como já mencionado, declarou seu apreço pelo jornal "lendo um dos números das suas folhas, de que sou leitor grátis" (O UNIVERSAL, 1825c). Um outro, provável morador de Ouro Preto, cujo codinome era Seu Constante Leitor, solicitava ao redator do mesmo jornal que não deixasse de escrever pois teria ele "muitos apaixonados" pela folha (O UNIVERSAL, 1825d).

É certo que, além de instrumento possibilitador da criação de uma rede de sociabilidade que ia além das fronteiras geográficas do extenso país, prazer propiciado pelo ato de ler, a leitura também poderia despertar outros sentimentos. Segundo um leitor de O Universal, a leitura de umas cartas publicadas Ihe teria causado tanto desconforto que segundo o mesmo lhe "exaltou a bílis ao ler as correspondências de um Paraopebano e as reflexões do Redactor do Diário Fluminense n.. 26, 29, 30 e 31, e Spectador no 147" (O UNIVERSAL, 1825a).

A leitura vista pelo mineiro oitocentista, aparece como instrumento de reflexão que leva à ação consciente e crítica. Contudo, falar de uma nova cultura da leitura e do escrito na província de Minas seria um exagero. O que é possível afirmar, baseado em pesquisadores da história cultural de Minas Gerais é que o universo cultural da província durante o desenrolar do Império brasileiro até a proclamação da república, embora tímido, se comparado ao da corte, foi consideravelmente importante como elemento deformação de um ambiente político dinâmico que envolvia, através dos usos da leitura do escrito, não apenas as elites mas também uma população de indivíduos menos letrados. 


\section{CONSIDERAÇÕES FINAIS}

Mesmo em número reduzido as bibliotecas públicas foram responsáveis por facilitar o acesso dos habitantes da província à leitura, onde não havia um significativo comércio livreiro, mas também por tentar moldar a leitura a ser realizada pelo leitor a um certo modo correto de ler, ao exigir, por meio de regulamentos, uma determinada postura adequada àquele recinto especificamente voltado para tal atividade.

Os periódicos propagaram, por toda a província, discursos políticos, poesias, contos e crônicas, folhetins e novelas. E foram também responsáveis pela articulação de uma rede de leitores e comunicadores ao conectar pessoas em diferentes espaços, com diferentes demandas. $O$ impresso, paulatinamente, invadiu o cotidiano da população dos mais diferentes recantos, tornando-se o "livro do povo", de modo que o dia a dia de pessoas de diferentes classes sociais foi modificado com a disseminação das práticas de ler. Mesmo porque hoje compreende-se a leitura não como simples decodificação de signos, mas também como interação social de interpretações e ideias conforme praticadas em praças públicas e nas sociedades literárias, locais de circulação e compartilhamento da leitura do escrito.

Os jornais ainda foram responsáveis por articular uma importante rede de comunicação entre leitores, editores, vendedores e anunciantes. Por meio desses periódicos foi possível alcançar lugares distantes e pessoas desconhecidas. Através das correspondências criou-se um canal de denúncias, de participação política e de sociabilidade.

A leitura, como pode ser percebido na análise de periódicos mineiros do século XIX, parece ter-se configurado, até certo ponto, como um ato cotidiano de famílias de diferentes classes, sobretudo, as privilegiadas. Ela era realizada no aconchego do lar onde, em geral, o indivíduo lia sozinho e silenciosamente, como também nas bibliotecas, cujos regimentos, como se viu, exigiam uma postura do leitor; e nas praças públicas, onde jornais e folhetos eram lidos em voz alta para 
proveito de pessoas mais pobres e pouco ou nada letradas que foram, dessa maneira, inseridas de alguma forma no cenário político daquele momento de mudanças.

Os jornais contribuíram, assim, diretamente para a construção de um novo mundo da leitura na província mineira, disponibilizando aos seus leitores informações políticas, literárias, técnicas e publicitárias. Publicado uma, duas ou três vezes na semana, estas folhas incentivaram a discussão em torno de questões levantadas pelo redator, motivando a participação popular na vida dos arraiais, vilas e cidades. Tudo indica que o século XIX nas Gerais se configurou como um momento de efervescência política vivida por muitos leitores, fosse pela leitura do escrito ou pela leitura do mundo.

\section{REFERÊNCIAS}

ASTRO DE MINAS. São João Del Rey, 25 out. 1830.

ASTRO DE MINAS. São João Del Rey, n. 552, 9 jun. 1836.

ASTRO DE MINAS. São João Del Rey, n. 612, 27 out. 1831.

ASTRO DE MINAS. São João Del Rey, n. 682, 10 abr. 1832.

ASTRO DE MINAS. São João Del Rey, n. 8, 6 dez.1827.

ABREU, Márcia. Apatia, ignorância e desinteresse: uma história da leitura no Brasil? Revista do Programa de Pós-Graduação em Letras da Universidade de Passo Fundo, Passo Fundo, v. 2, n. 1, p. 83-98, jan./jun. 2006.

CAMPOS, Maria Augusta do Amaral. A marcha da civilização nas vilas oitocentistas de São João Del Rey e São José do Rio das Mortes - 1810/1844. 1998. Dissertação (Mestrado) - FAFICH (UFMG), Belo Horizonte, 1998.

CHARTIER, Roger. Leitura e leitores na França do Antigo Regime. São Paulo: Unesp, 2004. 
Flávia Silvestre Oliveira; Maria da Conceição Carvalho

Práticas leitoras em Minas Gerais, século XIX: bibliotecas públicas e a leitura de jornais

CHARTIER, Roger. Textos, impresso e leitura. In: HUNT, Lynn. A nova história cultural. São Paulo: Martins Fontes, 1992. p. 211-238.

DARNTON, Robert. A história da leitura. In.: BURKE, Peter (Org.) A escrita da história: novas perspectivas. São Paulo: Unesp, 1992. p.199236.

\section{LAJOLO, Marisa; ZILBERMAN, Regina. A formação da leitura no}

Brasil. São Paulo: Ática, 1998. 374 p.

LIVRO DA LEI MINEIRA. Lei n. 49. Regulamento n. 9. Tomo 2, part. 2, fol. n. 3, 1836.

MORAIS, Christianni Cardoso. Para o aumento da mocidade da nossa pátria: estratégias de difusão do letramento na vila de São João Del Rei (1824 - 1831). In: CONGRESSO BRASILEIRO DE HISTÓRIA DA EDUCAÇÃO, 2., 2002, Natal. Anais... Natal, 2002. Disponível em: <http://www.sbhe.org.br/novo/congressos/cbhe2/pdfs/Tema7/0791.pdf>. Acesso em: 18 dez. 2015.

MOREIRA, Luciano da Silva. Imprensa e política: espaço público e cultura política na província de Minas Gerais, 1828-1842. 2006. Dissertação (mestrado) - Fafich/UFMG, Belo Horizonte, 2006.

MOTTA, Rosemary Toffani. Baptista Caetano de Almeida: um mecenas do projeto civilizatório em São João del-Rey no início do século XIX - a biblioteca, a imprensa e a sociedade literária. 2000. Dissertação (Mestrado) - Escola de Ciência da Informação, UFMG, Belo Horizonte, 2000.

ROBILLARD, Laryssa; RAMOS, Iris. O surgimento de Vila Rica. Disponível em: <http://cidademuseu.blogspot.com.br/2008/10/osurgimento-da-vila-rica.html>. Acesso em: 18 jan. 2016.

O SUL DE MINAS. Itajubá, n. 11, 1 out. 1859.

O UNIVERSAL, Ouro Preto, 28 mar. 1831.

O UNIVERSAL. Ouro Preto, n. 18, 26 ago. 1825a.

O UNIVERSAL. Ouro Preto, n. 21, 16 set. 1825b.

O UNIVERSAL. Ouro Preto, n. 49, 7 nov. 1825c.

O UNIVERSAL. Ouro Preto, n. 5, 7 jul. 1825d.

VILLALTA, Luiz Carlos. Vida privada e colonização: o lugar da língua, da instrução e dos livros. In: SOUZA, Laura de Mello (Org.). História da vida privada no Brasil. São Paulo: Companhia das Letras, 1997. v. 1, p. 331-385. 
WALSH, Robert. Notícias do Brasil -1828/1829. Belo Horizonte: Itatiaia, 1985.

\section{Title}

Reading practices in Minas Gerais during the XIX century: public libraries and newspaper reading

\section{Abstract:}

Introduction: The lift end of the ban on any press activity in Brazil, 1808, led to the multiplication of newspapers sparking a new impetus not only to a political debate, but also to spread the practice of informational and literary reading.

Objective: Investigate the occurrence of reading practices in Minas Gerais, in the 19th century, particularly the newspapers reading in public libraries of the cities of Ouro Preto and São Joãodel Rei.

Methodology: It was undertaken a literature review on History of Reading dialoguing with Darnton, Chartier, Abreu, Lajolo and Zilberman. A documentary research has been done involving the use of local newspapers as well as official documents and memoirs of foreign travellers, followed by textual analysis.

Results: Even though in a small number Minas Gerais libraries were responsible for facilitating the access of the province inhabitants to reading practices. Newspapers reading, in particular, articulated an important network of communication between readers, publishers and advertisers, creating a channel of political participation and sociability between citizens of different brazilian towns.

Conclusions: Minas Gerais social scenery in that moment, as was already happening since the 18th century, on the occasion of the conspiracy movements, did reading newspapers an everyday act lived by individuals of different social classes. In fact, in libraries and literary societies, such as in public squares, diaries and leaflets were read aloud for the benefit of poor and illiterate people who were, in this manner, socially inserted in that moment of social and political changes.

Keywords: Minas Gerais. Reading history. 19th century. Public libraries. Reading newspapers. 19th century.

\section{Titulo}

Practicas lectoras en Minas Gerais siglo XIX: bibliotecas públicas y la lectura de periódicos 


\section{Resumen}

Introducción: El fin de la prohibición de toda y cualquier actividad de imprenta en Brasil, 1808, provoco la proliferación de la publicación de periódicos y deflagró um nuevo impulso para los debates políticos y la propagación de la práctica de la lectura informativa y literaria.

Objetivo: Investigar el acontecer de las prácticas de lectura en Minas Gerais em el siglo XIX, especialmente de la lectura de periódicos en bibliotecas públicas de las ciudades de Ouro Preto y São João del Rei.

Metodología: Revisión de literatura sobre el tema de la historia de la lectura, dialogando sobre todo com Darnton, Chartier, Abreu, Lajolo y Zilberman. Esa investigación, con características de estúdio micro-histórico definió para la recolección de datos periódicos locales del XIX, así como documentos oficiales y apreciaciones de viajeros extranjeros. Como instrumento de análisis de los datos se utilizó el análisis documental.

Resultados: Las bibliotecas públicas fueron responsables por facilitar el acceso de los habitantes de la provincia a la lectura, en especial la lectura de periódicos, publicados en número considerable em ciudades de la provincia mineira. A través de las columnas del lector se creó un canal de participación política y de socialización entre ciudadanos de diferentes ciudades del país.

Conclusiones: La sociedad mineira del siglo XIX, como ya venía sucediendo desde el XVIII, hizo de lalectura de periódicos um acto cotidiano, vivenciado por individuos de diferentes clases sociales. Em las bibliotecas y sociedades literarias, como em las plazas públicas, periódicos y folletos eran leídos en voz alta para provecho de personas más pobres e iletradas, que fueron de este modo incluídos em el escenario de dicho momento de câmbios sociales y políticos.

Palabras-clave: Minas Gerais. Historia de la lectura Siglo XIX. Bibliotecas públicas. Lectura de periódicos. Siglo XIX.

Recebido: 29.11.2013

Aceito: 15.03 .2016 